\title{
Literature Review of International Anti-Money Laundering Research: A Scientometrical Perspective
}

\author{
Dexiang Mei, Yanyan Ye, Zengan Gao \\ School of Economics and Management, Southwest Jiaotong University, Chengdu, People's Republic of China \\ Email: meidexiang1101@126.com
}

Received 17 October 2014; revised 21 November 2014; accepted 13 December 2014

Copyright (C) 2014 by authors and Scientific Research Publishing Inc.

This work is licensed under the Creative Commons Attribution International License (CC BY). http://creativecommons.org/licenses/by/4.0/

c. (i) Open Access

\begin{abstract}
Based on the information visualization technology and the Web of Science database, which includes English research articles on anti-money laundering and counter-terrorism financing from 1993 to 2013, this paper explores the law and development status and research focus of international anti-money laundering research by analyzing national distribution, authors' distribution, organization distribution, cited journals, keywords, and situation to be cited by literatures (19932013) on money laundering with CiteSpace II application.
\end{abstract}

\section{Keywords}

Anti-Money Laundering, Scientometrics, Hot Field

\section{Introduction}

Money laundering is the processing of these criminal proceeds to disguise their illegal origin. This process is of critical importance, as it enables the criminal to enjoy these profits without jeopardising their source [1]. Financial action task force (FATF) is an independent inter-governmental body founded by G-7 summit in Paris in July 1989. The financial action task force (FATF) develops and promotes policies to protect the global financial system against money laundering and terrorist financing. The original FATF Forty Recommendations were drawn up in 1990 as an initiative to combat the misuse of financial systems by persons laundering drug money. In 1996 the Recommendations were revised for the first time to reflect evolving money laundering typologies. The 1996 Forty Recommendations have been endorsed by more than 130 countries and are the international anti-money laundering standard ${ }^{1}$. After the "9/11" terrorist attacked in the United States, the FATF expanded its mandate to

\footnotetext{
${ }^{1}$ The research is sponsored by the National Social Science Foundation of China (NO. 12XJY028) and the Humanities and Social Sciences Foundation of the Ministry of Education, People's Republic of China (NO. 11YJA790033).
} 
deal with the issue of the financing of terrorism, and took the important step of creating the Eight Special Recommendations on Terrorist Financing in October 2001. These Recommendations contain a set of measures aimed at combating the funding of terrorist acts and terrorist organizations, which are complementary to the Forty Recommendations. To take into account the continued evolution of money laundering techniques, the FATF Recommendations were again reviewed in 2003. In October 2004, the FATF published a ninth Special Recommendation. At last $40+9$ recommendations came out formally and were generally accepted and recognized as the international standards of anti-money laundering (AML) and counter-terrorism financing (CTF) by more than 180 countries and regions of the world. On February 16, 2012, the original $40+9$ recommendations were revised, and the new 40 recommendations emphasizing risk-based approach were passed, which comprehensively expounded new threats of the anti-money laundering, anti-terrorism and proliferation financing. In 2013, FATF announced the risk assessment rules of country's money laundering and terrorist financing. The anti-money laundering research has begun to take shape, with so many years' development of theory and practice work on of AML and CTF directed by FATF. This article selects articles on AMF and CFT research published from 1993 to 2013 (closing date August 2013) from the Science Citation index database Web of Science (WoS), and tries to show the overall map, emerging trend and transient patterns of the world anti-money laundering and counter-terrorism financing research scientifically, objectively, systematically and vividly by visualization software CiteSpace II, and then provide valuable enlightenment for the research on scholars in the field.

\section{The Theoretical Basis and Data Sources}

\subsection{The Theoretical Basis}

CiteSpace II is the second generation Java application for visualizing and analyzing emerging trends and patterns in scientific literature, developed by Dr. Chaomei Chen at College of Information Science and Technology in American Drexel University. It is a multivariate, time sharing, and dynamic information visualization software which is able to show the intellectual base, research front, development situation, knowledge transition and evolution process of a subject or research field on a knowledge map easily and clearly. Each colorful ring is a node of the network on behalf of the author, the country, or cited reference and so on. The links between nodes implies the cooperation relationship between authors, institutions or the co-cited relationship between scientific literatures or periodical journals. Citation tree-rings represent the citation history of an article. The color of a citation ring denotes the time of corresponding citations. The thickness of a ring is proportional to the number of citations in a given time slice.

CiteSpace II combines scientometrics with knowledge visualization techniques with the method of citation analysis. In general, a citation implies a relationship between a part or the whole of the cited document and a part or the whole of the citing document [2]. Citation analysis is that area of bibliometrics which deals with the study of these relationships [3]. A definition of co-citation in terms of set theory notations was given by Small. If $A$ is the set of papers which cites document $A$ and $B$ is the set which cites $B$, then $A \cap B$ is the set which cites both $a$ and $b$. The number of elements in $A \cap B$, that is $n(A \cap B)$, is the co-citation frequency. The relative co-citation frequency could be defined as $n(A \cap B) \div n(A \cup B)[4]$. Small and Griffith represented currently activated scientific specialties as clusters of co-cited articles [5]. CiteSpace II provides clusters of articles co-cited (keywords co-occurrence) by analyzing the co-cited (co-occurrence) relationship between articles to shows the research status of a certain subject areas.

A commonly used centrality metric is the betweenness centrality [6]. It measures the percentage of the number of shortest paths in a network that a given node belongs to. Nodes with high-betweenness centrality tend to be found in paths connecting different clusters. Through CiteSpace II, the structural properties of a node are displayed in terms of a purple ring. And the purple rims of nodes indicate the importance of nodes in terms of betweenness centrality $(\geq 0.1)$ [7]. The thickness of the purple ring indicates the degree of its betweenness centrality, which is a measure associated with the transformative potential of a scientific contribution. Such nodes tend to bridge different stages of the development of a scientific field [8] [9].

\subsection{Data Source}

The input data for CiteSpace II was retrieved from citation index databases via WoS (SSCI, SCI-Expanded, the CPCI-S database) based on a topic search for articles published between 1993 and 2013 on money laundering or 
terrorist financing. The scope of the search included four topic fields in each bibliographic record: title, abstract, descriptors, and identifiers. The search was limited to articles in English only. The resultant dataset contains a total of 557 records including article, proceedings paper, book review, editorial material. With corresponding threshold setting CiteSpace II produced the following charts and figures.

\section{Analysis and Results}

\subsection{The Knowledge Map of Countries and Districts in International AML Studies}

Drawing visualized knowledge mapping of countries and districts in worldwide AML studies can discover the distribution of international AML research institutions and persons and reflect a country's impact upon AML efforts to some extent. From Table 1, we can see that USA with 97 papers has become the leading country in the field of AML research since she paid the earliest attention to money laundering and executed criminal legislation. Accordingly, China, 42 papers, is ranked second, and has achieved a rapid development after 2007 thanks to her FATF membership and enactment of first anti-money laundering law in the same year. England, Germany, Australia, Romania, Canada, Netherland, Italy, and Ukraine are the major countries of AML studies. As shown in Figure 1, the international cooperation in AML research is found between USA and Switzerland, USA and Canada, England and Wales, England and Netherland, Poland and Finland, and China and Germany, and other countries and districts have not cooperated yet.

\subsection{The Knowledge Map of Authors in International AML Studies}

The knowledge map of international authors who study anti-money laundering can, to a certain degree, illustrate the influence and significance of different authors and reflect their contributions to AML research. As shown in Table 2, Hetzer is a very pivotal node in the network with the cited frequency for 10 times, indicating that Hetzer occupies a crucial position in world AML research and plays the most important part. Other authors like Dongming Xu, Shijia Gao, Ping Song, Pengzhu Zhang, Agus Sudjianto, Thomas Naylor, J. C. Sharman, and Jun Tang have relatively higher frequency of citation and far-reaching influence in this field. The cooperation among different authors is also shown in Figure 2. The co-authorship usually exists in the team of DD Lin \& R. Xue; Bin Feng, Ping Song \& Yang Qifeng; Shijia Gao \& Dongming Xu; Agus Sudjianto, Caroline Ziemkiewicz \& Alvin Lee; and Oana Andreea Pirnuta, Alina Adriana Arseni, Cosmina Oana Draghic \& Gabriel Florin Moisescu. But there is short of interdiscipline and inter-subject cooperation, which may be a limit to furthering international AML research That's why further development of the international anti-money laundering research has been limited.

Table 1. Top 10 most productive countries/districts in global AML research 1993-2013.

\begin{tabular}{ccccc}
\hline Country & Frequency & Country & Fomania & Rrequency \\
\hline USA & 97 & Canada & 17 \\
China & 42 & Netherlands & Italy & 13 \\
England & 39 & Ukraine & 10 \\
Germany & 21 & 19 & 10 \\
\hline
\end{tabular}

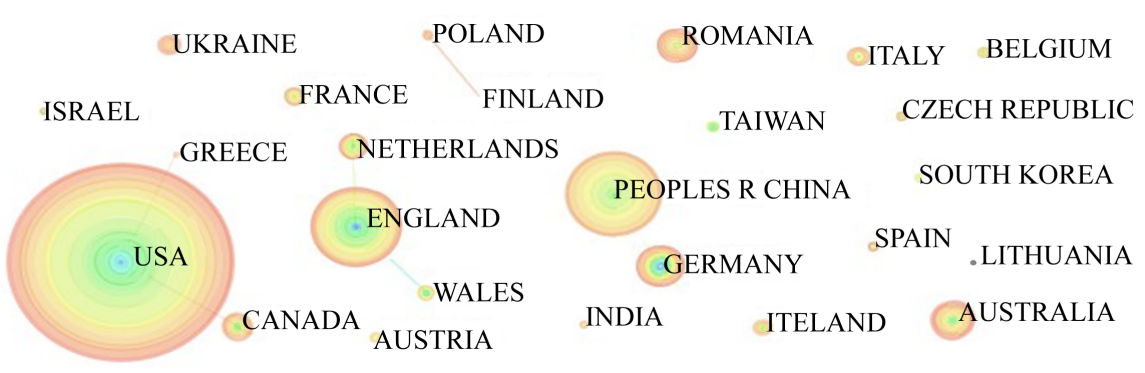

Figure 1. The knowledge map of countries/districts in Global AML research 1993-2013. 
Table 2. Top 10 most productive authors in global AML research 1993-2013.

\begin{tabular}{cccc}
\hline Author & Frequency & Author & Frequency \\
\hline [Anonymous] & 10 & Pengzhu Zhang & Agus Sudjianto \\
W. Hetzer & 10 & Thomas Naylor & 4 \\
Dongming Xu & 5 & J. C. Sharman & 3 \\
Shijia Gao & 4 & J. Tang & 3 \\
Ping Song & 4 & & 3 \\
\hline
\end{tabular}

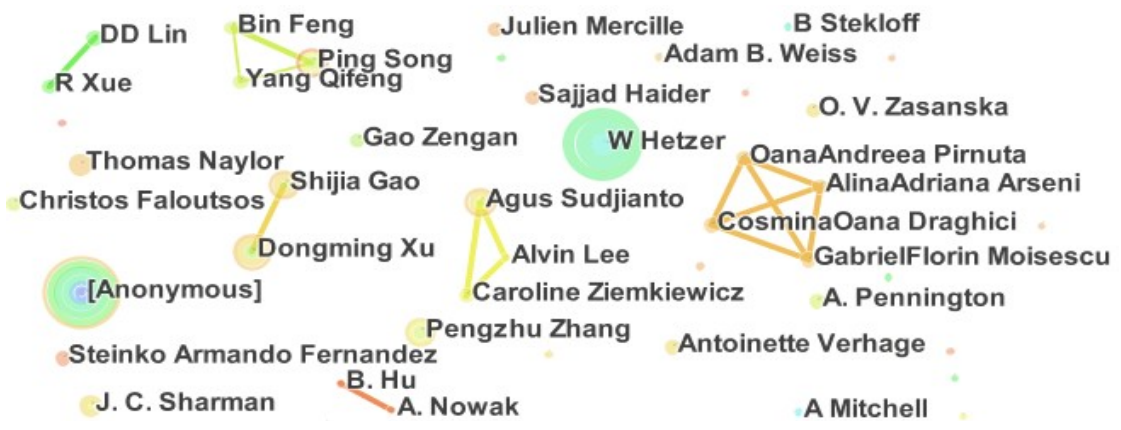

Figure 2. The knowledge map of authors in global AML research 1993-2013.

\subsection{The Knowledge Map of Institutions Studying Anti-Money Laundering}

The knowledge map of institutions which study anti-money laundering can reveal the institutions' influence and their position in this field and show the active institutions focusing on anti-money laundering research. As shown in Table 3, Wuhan University of Technology is currently ranking first with 7 articles in this field, and then followed by Cardiff University, University of Queensland, University of London, etc. And the colleges and universities become the major force of the international anti-money laundering research. The next is the bank. We can come to a conclusion that implying that AML has converted from banking practice into theoretical studies by higher education institutions. Besides in Figure 3, cooperation is only found between CERI Sciences Po and CNRS, indicating that international AML research cooperation is in short, which suggests that there is rarely cooperative relationship in this knowledge domain.

\subsection{The Knowledge Map of International Journals in the Field of Anti-Money Laundering Research}

The network map of cited journals was provided by CiteSpace II through the cited journal function (as shown in Figure 4). The size of the nodes in the graph reflects the amount of journals cited by other literature. The bigger the nodes are, the higher frequency of which they are cited the larger the influence and higher position they have in the field of anti-money laundering research. As shown in Figure 4 and Table 4, "Journal of Money Laundering Control" ranks in the first place among all the journals with cited frequency for 51 times. "Journal of Money Laundering Control" is the only periodical specializing in the field of anti-money laundering research in the world currently and plays a prospective and guiding role in revolution, innovation and development. It's considered to present the mainstream and the latest development of international anti-money laundering research. "Crime, Law and Social Change" ranks the second with cited frequency for 48. It's a periodical on financial crime, political corruption, environmental Crime, resources occupation so that it became the main platform for scholars to research anti-money laundering from the perspective of legislation and its predicate crime in the early days (the 1990s). The common feature for "Journal of Money Laundering Control" and "the Crime Law and Social Change" is that their cited frequency is quite high and their betweenness centrality are higher than 0.1 as the key nodes in graph., which further proves that the two academic journals are at the important position in the international study of anti-money Laundering. "Lecture Notes in Computer Science" is at the third place with the cited frequency for 32 times. With the development of Computer technology, anti-money laundering experienced an important combination in computer technology, especially the application of data mining in the 
Table 3. Top 12 most productive institutions in global AML research 1993-2013.

\begin{tabular}{cccc}
\hline Institution & Frequency & Institution & Frequency \\
\hline Wuhan Univ. Technol. & 7 & McGill Univ. & 4 \\
Cardiff Univ. & 5 & Griffith Univ. & 4 \\
Univ. Queensland & 5 & Bank Amer. & 3 \\
Univ. London & 5 & Carnegie Mellon Univ. & 3 \\
Florida Int. Univ. & 4 & Univ. Virginia & 2 \\
Univ. Coll. Dublin & 4 & SW Jiaotong Univ. & \\
\hline
\end{tabular}

Table 4. Journals with cited frequency for 20 or more in global AML research 1993-2013.

\begin{tabular}{cccc}
\hline Frequency & Centrality & Year & Journal \\
\hline 51 & 0.14 & 2006 & Journal of Money Laundering Control \\
48 & 0.11 & 1991 & Crime, Law and Social Change \\
32 & 0.05 & 1999 & Lecture Notes in Computer Science \\
30 & 0.19 & 1989 & American Criminal Law Review \\
27 & 0.13 & 1997 & International Organization \\
25 & 0.19 & 2002 & Journal of Financial Crime \\
23 & 0.07 & 1985 & Communications of the ACM \\
20 & 0.02 & 1987 & Pacific Law Journal \\
20 & 0.24 & 1976 & Foreign Affairs \\
\hline
\end{tabular}

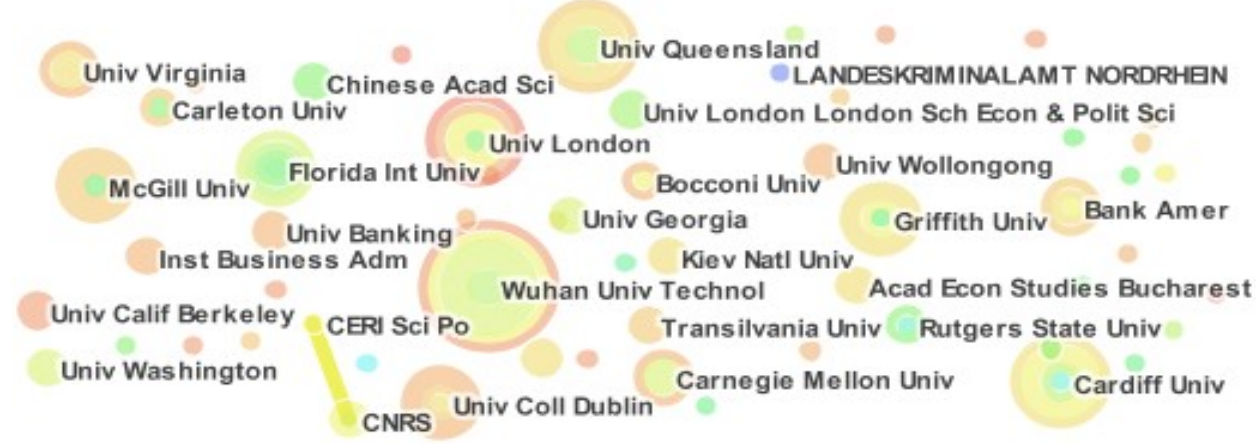

Figure 3. The knowledge map of institutions in global AML research 1993-2013.

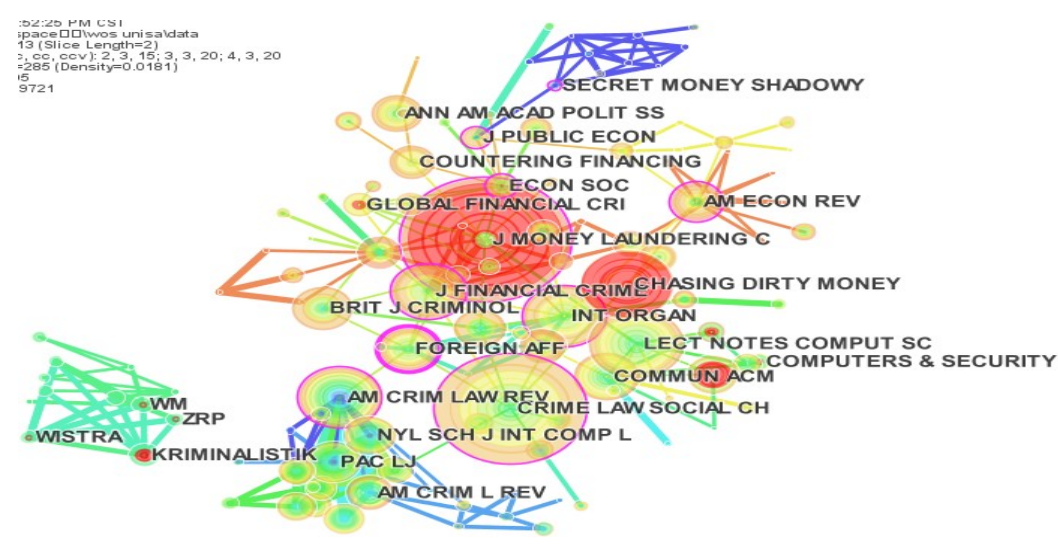

Figure 4. The knowledge map of journals in global AML research 1993-2013. 
identification of money laundering which has become an important topic of the anti-money laundering study. "American Criminal Law Review" ranks the fourth with cited frequency for 30 times. "American Criminal Law Review" is the most important magazines on Criminal Law research. The United States is in the leading position in the anti-money laundering research, formulation of relevant laws and regulations as well as the construction of anti-money laundering system in the world. So this Criminal Law journal gains much attention from the international anti-money laundering research field. "International Organization" ranks the fifth with cited frequency for 27 times, which is a review journal studying international affairs and plays an important role in this field. Money laundering crime often involves in drug trafficking, terrorist financing and other criminal activities, which is often accompanied by the fund flow between countries. So it has become a crucial international problem to realize the cooperation between countries to fight against money laundering. In addition, some of the foreign periodicals such as "Journal of Financial Crime", "Communications of the ACM" have quite high influence in international anti-money laundering research.

\subsection{The Keywords Analysis}

Keywords search is an effective method of document retrievals for keyword is the important component of academic papers. They provide a detailed account of the field of science studied, reveal the rich detail of more heterogeneous fields or document set, and expose the network of concepts (and the like) to the fullest comprehensible extent [10].

Table 5 and Figure 5 show that anti-money laundering research mainly concentrates on the following aspects: (1) on the aspect of fighting against the predicate crimes of money laundering, the keywords are crime, corruption, terrorism, terrorism financing, drug addiction et al; (2) on the aspect of anti-money laundering regulation, the keywords are compliance, risk, financial monitoring, governmentality, global governance, banking system; (3) on the aspect of money laundering monitoring with the help of computer technology, the keywords are

\section{Table 5. The keywords with high frequency and high betweenness centrality in global AML research 1993-2013.}

\begin{tabular}{|c|c|c|c|c|c|}
\hline Frequency & Centrality & Keywords & Frequency & Centrality & Keywords \\
\hline 66 & 0.43 & money laundering & 6 & 0.05 & fraud detection \\
\hline 22 & 0.34 & terrorism & 6 & 0.15 & terrorism financing \\
\hline 19 & 0.16 & anti-money laundering & 5 & 0.01 & security \\
\hline 11 & 0.01 & crime & 5 & 0.06 & electronic cash \\
\hline 11 & 0.03 & data mining & 5 & 0.06 & enforcement \\
\hline 9 & 0.01 & politics & 4 & 0.01 & compliance \\
\hline 9 & 0.08 & corruption & 4 & 0.01 & risk \\
\hline 8 & 0.08 & globalization & 4 & 0.04 & intelligence \\
\hline 6 & 0.01 & shadow economy & 4 & 0.13 & networks \\
\hline 6 & 0.02 & state & 3 & 0.14 & classification \\
\hline
\end{tabular}

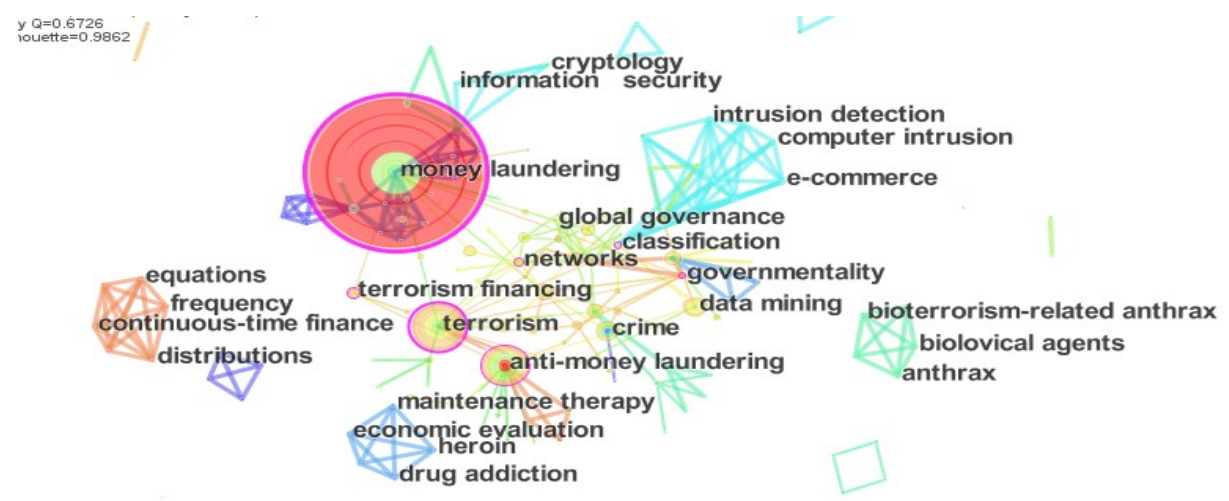

Figure 5. The knowledge map of co-occurrence keywords in global AML research 1993-2013. 
software solutions, intrusion detection, computer intrusion, cryptology, information security, data mining. To combat the predicate crimes such as drug crime, terrorist financing and so on, anti-money laundering gets much attention from countries around the world. Therefore, the research on the predicate crimes of money laundering has always been a research focus in the field of anti-money laundering research. And in order to improve the effectiveness of work on combating money laundering, emphasis is placed on practical research in this field. The close relationship between banks and cash make it become the sector with high possibility to be made use by money laundering crime and the key object in anti-money laundering research. It's quite rational that construction of a national regulatory system and the implementation of the supervision mechanism centered upon the banking sector. Moreover an efficient supervision means a relatively accurate risk rating system and ability to recognize suspicious transactions behavior, which is dependent on the computer technology, especially data mining, information security, etc.

\subsection{The Co-Cited Literature Analysis}

A progressive co-citation analysis takes multiple co-citation networks from consecutive time intervals as input and produces a merged network to represent the evolution of the underlying domain [11]. The cluster of co-cited documents is considered to represent the knowledge base of the specialty: the key concepts, methods, or experiments that researchers build on [12] [13]. Table 6 indicates the international research literatures on AML with higher frequency of being cited and centrality, and Figure 6 is the network knowledge map of cited reference clusters.

Label terms are selected from titles, keywords, or abstracts of articles that specifically cite members of the cluster. If the members of a cluster represent the footprints of an invisible college or a paradigm, the labels reflect what the invisible college and the paradigm. These terms are ranked by three different algorithms: tf * idf, log-likelihood ratio (LLR) tests, and mutual information. Labels selected by tf * idf weighting tend to represent the most salient aspect of a cluster, whereas those chosen by log-likelihood ratio tests and mutual information tend to reflect a unique aspect of a cluster. Through the automatic clustering function three hot topics on anti-money laundering research are produced by CiteSpace II according to the $\mathrm{tf} *$ idf algorithm, which are the predicate crime research, money laundering risk research, anti-money laundering research in Germany.

The biggest cluster 26 contains 46 nodes including two pivotal points and 5 nodes with cited frequency higher than 15 times. This cluster is about the predicate crime and legislation of anti-money laundering study from the identifiers "crime", "police cooperation", "international" and so on. GR Strafer's "money laundering: the crime of the 90s" with cited frequency up to 23 times outlines the roots of the original 1986 legislation, summarizes the elements of the new "money laundering" offenses, discusses the interpretive problems likely to be encountered by the court and practitioners confronted with these provisions, and finally discusses some of the recent changes in the legislation and proposes changes to the statue that would guarantee constitutionality and provide sufficient standards to ensure criminal activity and not innocent business transactions punished by statutes [14]. The other pivotal point in the network "Money laundering: a new international law enforcement model" gives a

Table 6. The literatures with cited frequency for 12 or more in global AML research 1993-2013.

\begin{tabular}{cccl}
\hline Frequency & Centrality & Year & Cited Reference \\
\hline 27 & 0.05 & 2004 & Truman, E.M. Chasing Dirty Money: The Fight against Money Laundering \\
23 & 0.05 & 1989 & Strafer, G.R. Money Laundering: The Crime of the 90s \\
20 & 0.03 & 1987 & Irvine, M.R. Money Laundering Control Act of 1986: Tainted Money and the Criminal Defense Lawyer \\
18 & 0.02 & 1988 & Harmon, J.R. and James, D. United States Money Laundering Laws: International Implications \\
14 & 0.12 & 2000 & Stessens, G. Money Laundering: A New International Law Enforcement Model \\
14 & 0 & 1994 & $\begin{array}{l}\text { Razzano, F.C. American Money Laundering Statutes: The Case for a Worldwide System of } \\
\text { Banking Compliance Programs }\end{array}$ \\
13 & 0.16 & 2000 & $\begin{array}{l}\text { Adams, T.A. Tacking on Money Laundering Charges to White Collar Crimes: What Did Congress } \\
\text { Intend, and What Are the Courts Doing }\end{array}$ \\
12 & 0 & 1993 & Elizabeth, J. Money Laundering: Business Beware \\
12 & 0 & 1984 & Kaufman, I.R. Cash Connection: Organized Crime, Financial Institutions, and Money Laundering \\
& 0 & 2001 & Andres, R. International Money Laundering Law Enforcement \& the USA Patriot Act of 2001
\end{tabular}




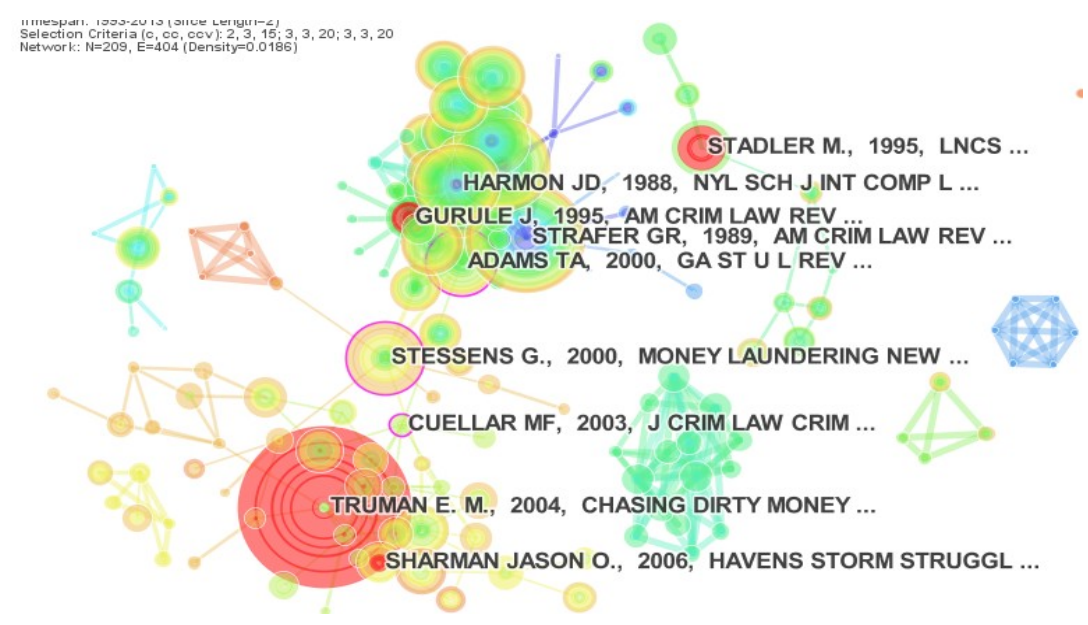

Figure 6. The network map of co-cited literature in global AML research 1993-2013.

broad analysis of the legal issues raised by the international fight against money laundering and offers an extensive comparative research of the criminal and preventive law aspects from an international perspective [15]. Most of this volume is devoted to specific legal problems that spring from the international nature of the money laundering phenomenon. It contains the most detailed overview yet published on the rules and practices of international co-operation in the fight against money laundering, and the jurisdictional questions that inevitably arise in this context. The two pivotal points reveal that this cluster conducts a series of research and summary on the legislation of anti-money laundering laws and regulations from the aspects of money laundering crime, predicate offence, legal subject, legal liability, legal force and international cooperation.

The second big cluster 24 contains 37 nodes including a pivotal point and one with cited frequency higher than 15 . We come to the conclusion that this cluster studies the money laundering risk in view of identifiers risk, Europe, economy et al. "The Tenuous Relationship Between The Fight Against Money Laundering and The Disruption of Criminal Finance" Cuellar explains some ways that money's illegal origin is hidden and by explaining the tangle of laws and regulations designed to interfere with that process and introduce both theoretical justifications and the legislative and executive history [16]. And then this literature uses quantitative and qualitative data to contrast the consequences of the fight against laundering with the lofty objectives of disrupting criminal finance cited by legislators and executive branch officials, finding that that criminal penalties for money laundering are used overwhelmingly against people already subject to punishment for a predicate offense and coming to the conclusion that the relationship between anti-money laundering and disrupting criminal finance is tenuous. It's of high value in directing the future theoretical and practical research, for this literature point out the tenuous relationship between AML and combating criminal finance whereas the initial motivation of AML is to control the predicate crime. This literature is the pivotal point in the cluster 24 , playing a significant role in the linkage between 24 and 26. This paper continues the cluster 26's research on anti-money laundering law and regulation system paying more attention to the effectiveness of anti-money laundering regulatory in the meantime. The biggest node in the cluster "The Chasing Dirty Money: The Fight against Money Laundering" with cited frequency for 27 is put forward by Truman [17]. Reuter and Truman (1) explore what is known about the scale and characteristics of money laundering, they point that the vagueness of such estimates and of weaknesses in the techniques used to quantify it and estimated changes in the volume of money laundered cannot be used as a measure to judge the effectiveness of the global anti-money laundering regime; (2) describe the current antimoney laundering regime of the US and compares it with other countries; (3) develop a framework for assessing the effectiveness of the regime relying on indirect indicators such as suspicious activity reports, prosecutions and convictions, forfeitures and seizures and prices for money-laundering services; and then (4) use that framework to assess how well the current system works and make proposals for its improvement. The cluster analyzes the effectiveness of anti-money laundering system by measurement the incremental or decrement of money laundering and discusses how well this method works. Obviously, anti-money laundering research is no longer limited to study the legal system of anti-money laundering, but evolves in more directions.

The third big cluster 24 contains 15 nodes representing the literatures of Hetzer, Meyer, Bersmann. Besides, 
the literatures from Hetzer are cited up to11times. We come to the conclusion that this cluster studies the money laundering risk in view of identifiers risk, Europe, economy et al. The cluster shows the study of the three German scholars with the representative Hetzer mainly concentrate on the predicate offences of anti-money laundering, especially organized crime, financial crime ( the year of nodes in this clusters are almost during 1990 and 2000). He points out the vital function of combat money laundering on controlling the predicate offences as well as the role that BKA plays in fighting money laundering crime and puts forward the corresponding legal countermeasure on the basis of exploring the close relations between financial crime, organized crime, tax evasion and money laundering. Hetzer holds that, with globalization, deregulation, and constantly evolution in financial market, money laundering problems has stepped into a new situation that new financial tools such as financial derivatives are used by money launders [18]-[23].

\section{Conclusions}

Based on the information visualization technology, we explore the law and status of development and research focus of international anti-money laundering research by analyzing the nationality, author, institution, situation to be cited of literatures on money laundering collected by WoS database with the help of CiteSpace application.

The United States is at the leading position in the international anti-money laundering research field, followed by China, Britain, Germany, Australia, respectively, Romania, Canada, the Netherlands, Italy and Ukraine, all of which are the main force in the field of anti-money laundering research. In addition, Hetzer, Xu, Gao, Song, Zhang, Sudjianto, Naylor, Sharman and Tang play an important role and have extensive and profound influence in this research field. "Journal of Money Laundering Control" is the only periodical specializing in the field of anti-money laundering research in the world currently and plays a prospective and guiding role in revolution, innovation and development. Other periodicals with much concern in this field are "Crime, Law and Social Change", "the section Notes in Computer Science", "the American Criminal Law Review" and "International Organization". In addition, some of the foreign periodicals, such as "Journal of Financial Crime" and "Communications of the ACM", have high influence in international anti-money laundering research field.

Through analyzing, inducing and summarizing the content of literatures with high cited frequency, we get three main research focuses in the field: (1) the research on predicate crimes of money laundering; (2) the research on anti-money laundering legislation; (3) the research on money laundering risk in Germany.

This paper has some practical meaning considering the data sources, research methods and the research result. Overall, this study is just an exploratory research with some deficiencies and needs to be improved in the future study because of the limitation of scope and amount literature collected by the database and some errors in literature retrieval, data statistic and processing.

\section{References}

[1] FATF What Is Money Laundering? http://www.fatf-gafi.org/pages/faq/moneylaundering/

[2] Malin, M.V. (1968) The Science Citation Index: A New Concept in Indexing. Library Trends, 16, 374-387.

[3] Smith, L.C. (1981) Citation Analysis. Library Trends, 30, 83.

[4] Small, H. (1973) Co-Citation in Scientific Literature: A New Measure of the Relationship between Publications. Journal of the American Society of Information Science, 4, 265-269. http://dx.doi.org/10.1002/asi.4630240406

[5] Small, H. and Griffith, B.C. (1974) The Structure of Scientific Literatures I: Identifying and Graphing Specialties. Science Studies, 4, 17-40.

[6] Freeman, L.C. (1979) Centrality in Social Networks: Conceptual Clarification. Social Networks, 1, 215-239. http://dx.doi.org/10.1016/0378-8733(78)90021-7

[7] Chen, C.M. (2006) CiteSpace II: Detecting and Visualizing Emerging Trends and Transient Patterns in Scientific Literature. Journal of the American Society for Information Science and Technology, 57, 359-377. http://dx.doi.org/10.1002/asi.20317

[8] Chen, C.M. (2009) Mapping Scientific Frontiers: The Quest for Knowledge Visualization. 2nd Edition, Springer, Berlin.

[9] Chen, C.M., Ibekwe-SanJuan, F. and Hou, J.H. (2010) The Structure and Dynamics of Co-Citation Clusters: A Multiple-Perspective Co-Citation Analysis. Journal of the American Society for Information Science and Technology, 61, 1386-1409. http://dx.doi.org/10.1002/asi.21309

[10] Whittaker, J. (1989) Creativity and Conformity in Science: Titles, Keywords and Co-word Analysis. Social Studies of 
Science, 19, 473-496. http://dx.doi.org/10.1177/030631289019003004

[11] Chen, C.M. (2004) Searching for Intellectual Turning Points: Progressive Knowledge Domain Visualization. Proceedings of the National Academy of Sciences of the United States of America, 101, 5303-5310. http://dx.doi.org/10.1073/pnas.0307513100

[12] Small, H. (1997) A Co-Citation Model of a Scientific Specialty: A Longitudinal Study of Collagen Research. Social Studies of Science, 7, 139-166. http://dx.doi.org/10.1177/030631277700700202

[13] Small, H. (1978) Cited Documents as Concept Symbols. Social Studies of Science, 8, 327-340. http://dx.doi.org/10.1177/030631277800800305

[14] Strafer, G.R. (1989) Money Laundering: The Crime of the 90's. American Crime Law Review, 27, 149-207.

[15] Stessens, G. (2000) Money Laundering: A New International Law Enforcement Model. Cambridge University Press, Cambridge. http://dx.doi.org/10.1017/CBO9780511494567

[16] Cuellar, M.F. (2003) The Tenuous Relationship between the Fight against Money Laundering and the Disruption of Criminal Finance. The Journal of Criminal Law and Criminology, 93, 311-466.

[17] Reuter, P. and Truman, E.M. (2004) Chasing Dirty Money: The Fight against Money Laundering. Oxford University Press, Oxford.

[18] Hetzer, W. (2001) Legislative Strategies_Economic Crime and Money Laundering. Kriminalistik, 55, $391-401$.

[19] Hetzer, W. (2001) Organized Crime and Money Laundering-Role of the German BKA in Controlling This Phenomenon. Kriminalistik, 55, 154-156.

[20] Hetzer, W. (1999) Economics and Crime-Law Enforcement Considerations on Business and Criminal Activity. Kriminalistik, 53, 570-578.

[21] Meyer, J. and Hetzer, W. (1997) Seizing Crime-Derived Assets_-Legal and Practical Problems in Controlling Organized Crime. Kriminalistik, 51, 31-36.

[22] Hetzer, W. (1999) European Impulses in Money Laundering-Fighting Tax Evaders and Money. Kriminalistik, 53, 788-793.

[23] Hetzer, W. (2003) Money Laundering and Financial Markets. European Journal of Crime, Criminal Law and Criminal Justice, 11, 264-277. http://dx.doi.org/10.1163/157181703322681104 
Scientific Research Publishing (SCIRP) is one of the largest Open Access journal publishers. It is currently publishing more than 200 open access, online, peer-reviewed journals covering a wide range of academic disciplines. SCIRP serves the worldwide academic communities and contributes to the progress and application of science with its publication.

Other selected journals from SCIRP are listed as below. Submit your manuscript to us via either submit@scirp.org or Online Submission Portal.
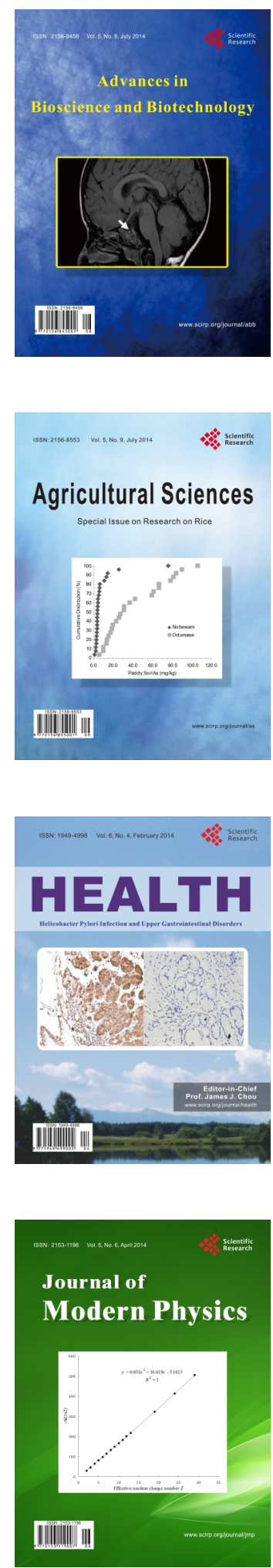
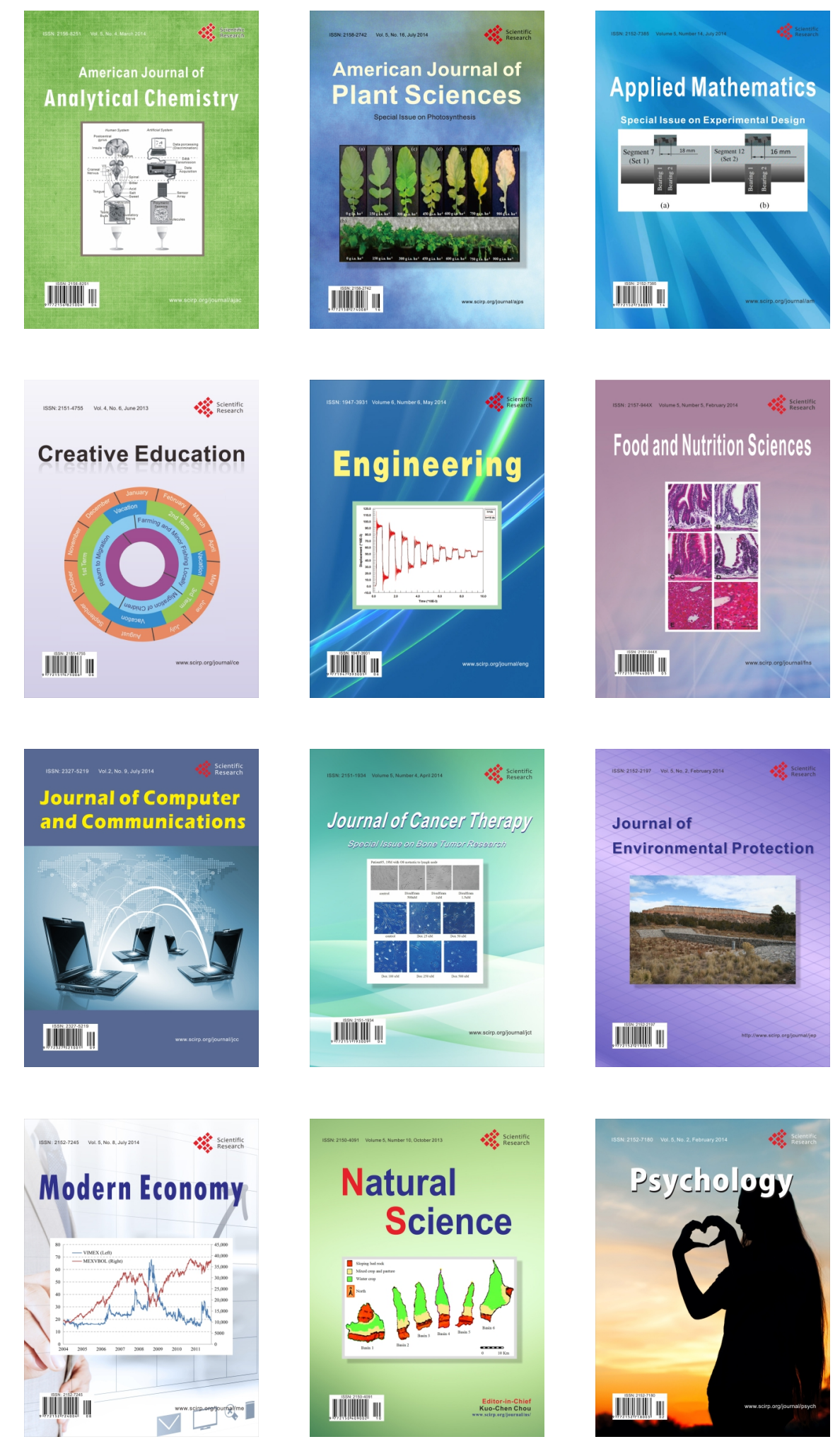